\title{
Quantitative CMR perfusion imaging identifies reduced flow reserve in microvascular coronary artery disease
}

\author{
Peter W Shaw ${ }^{1 *}$, Yang Yang ${ }^{2}$, Kelvin Chow², Jorge A Gonzalez ${ }^{1}$, Pelbreton C Balfour ${ }^{1}$, Craig H Meyer ${ }^{2}$, \\ Fred Epstein', Jamieson Bourque ${ }^{1}$, Michael Salerno ${ }^{1,2}$, Christopher M Kramer ${ }^{1,3}$ \\ From 19th Annual SCMR Scientific Sessions \\ Los Angeles, CA, USA. 27-30 January 2016
}

\section{Background}

Patients with angina without obstructive coronary artery disease are increasingly recognized and microvascular disease (MVD) is thought to play a significant role. An abnormal myocardial perfusion reserve (MPR) by positron emission tomography is predictive of increased cardiovascular events, particularly in women, diabetics, and those with metabolic syndrome. We hypothesized that MPR as measured by CMR would be reduced in patients with angina or anginal equivalent symptoms and nonobstructive $\mathrm{CAD} /$ normal coronaries compared with asymptomatic controls.

\section{Methods}

Patients (women, diabetics or those with the metabolic syndrome) with suspected microvascular disease and no significant epicardial stenosis $(\geq 50 \%)$ by $x$-ray angiography underwent vasodilator stress CMR perfusion studies on a 1.5T Siemens Avanto. Subjects without cardiovascular risk factors were recruited as controls and underwent the same vasodilator stress CMR study. High resolution first-pass spiral perfusion pulse sequences were performed. Sequence parameters included: 8 interleaves of variable density spirals from 0.75 to 0.2 Nyquist, $6.1 \mathrm{~ms}$ readout per interleaf, TE $1.0 \mathrm{~ms}$, TR $9 \mathrm{~ms}$, TI $80 \mathrm{~ms}$, FA 35, FOV $340 \mathrm{~mm}$, in-plane resolution $1.48 \mathrm{~mm}$. Perfusion images were acquired during rest and stress at 3 short axis slice locations. Images were reconstructed by SPIRIT and then aligned with non-rigid registration ANTs (Advanced Normalization Tools). Quantification of perfusion was

'Cardiology, University of Virginia, Charlottesville, VA, USA

Full list of author information is available at the end of the article performed on a pixel-wise basis using Fermi-function deconvolution.

\section{Results}

24 patients with MVD (20 female, 4 male, age (mean \pm SD) $56 \pm 13$ ) completed the stress CMR protocol and were compared to 9 control subjects (6 F, $3 \mathrm{M}$, age $47 \pm$ 13). Patients with MVD were predominantly Caucasian (79\%) with an average BMI of $32.3 \pm 6.6$ and had hypertension $(75 \%)$, dyslipidemia (88\%), current or prior tobacco use $(67 \%)$ and diabetes $(25 \%)$. Rest flow was $1.28 \pm 0.31 \mathrm{~mL} / \mathrm{min} / \mathrm{g}$ and stress flow $2.69 \pm 0.64 \mathrm{~mL} /$ $\mathrm{min} / \mathrm{g}$ with a resultant MPR of $2.15 \pm 0.44$. In controls, rest flow was $1.23 \pm 0.25 \mathrm{~mL} / \mathrm{min} / \mathrm{g}$ and stress flow 3.35 $\pm 0.61 \mathrm{~mL} / \mathrm{min} / \mathrm{g}$ with MPR of $2.75 \pm 0.32(\mathrm{p}<0.001$ vs. patients). Both subendocardial and subepicardial flow reserve were lower in patients than controls $(\mathrm{p}<0.001)$ (Table 1). Rest flow $(\mathrm{p}<0.01)$ and MPR $(\mathrm{p}<0.05)$ were lower in diabetics. In hypertensive patients, rest and stress flows were lower $(\mathrm{p}<0.05)$ but MPR was similar.

\section{Conclusions}

Patients with MVD and no significant epicardial coronary disease have reduced global MPR compared to asymptomatic controls as demonstrated by quantitative CMR

Table 1 Flow Values

\begin{tabular}{cccc}
\hline & $\begin{array}{c}\text { Rest Flow (mL/ } \\
\text { min/g) }\end{array}$ & $\begin{array}{c}\text { Stress Flow (mL/ } \\
\text { min/g) }\end{array}$ & MPR \\
\hline MVD ( $\mathrm{n}=24)$ & $1.28 \pm 0.31$ & $2.69 \pm 0.64$ & $2.15 \pm$ \\
& & & $0.44^{*}$ \\
Controls ( $\mathrm{n}=$ & $1.23 \pm 0.25$ & $3.35 \pm 0.61$ & $2.75 \pm$ \\
9) & & & 0.32 \\
\hline
\end{tabular}

${ }^{*} p<0.001$ vs. controls 
perfusion imaging, likely due, in part, to endothelial dysfunction. This may contribute to their chest pain syndrome and adverse cardiovascular prognosis. Quantitative CMR perfusion imaging is a promising approach for its identification.

\section{Authors' details}

${ }^{1}$ Cardiology, University of Virginia, Charlottesville, VA, USA. ${ }^{2}$ Biomedical Engineering, University of Virginia, Charlottesville, VA, USA. ${ }^{3}$ Radiology, University of Virginia, Charlottesville, VA, USA.

Published: 27 January 2016

doi:10.1186/1532-429X-18-S1-P79

Cite this article as: Shaw et al:: Quantitative CMR perfusion imaging identifies reduced flow reserve in microvascular coronary artery disease. Journal of Cardiovascular Magnetic Resonance 2016 18(Suppl 1):P79.

Submit your next manuscript to BioMed Central and take full advantage of:

- Convenient online submission

- Thorough peer review

- No space constraints or color figure charges

- Immediate publication on acceptance

- Inclusion in PubMed, CAS, Scopus and Google Scholar

- Research which is freely available for redistribution

Submit your manuscript at www.biomedcentral.com/submit 